\title{
Complexo de Carney esporádico com Schwannoma melanocítico e carcinoma papilífero de tireóide: relato de caso
}

\author{
Carney complex sporadic with Schwannoma melanocytic \\ and thyroid papillary carcinoma: case report
}

\author{
Luilson Geraldo Coelho Júnior'1, Débora Gonçalves da Silva²
}

Coelho Júnior LG, da Silva DG. Complexo de Carney esporádico com Schwannoma melanocítico e carcinoma papilífero de tireóide: relato de caso / Carney complex sporadic with Schwannoma melanocytic and thyroid papillary carcinoma: case report. Rev Med (São Paulo). 2016 jan.-mar.;95(1):33-6.

RESUMO: Complexo de Carney é uma forma rara de neoplasia endócrina múltipla familiar de herança autossômica dominante. Está associado à alteração de pigmentação cutânea e mucosa, doença nodular adrenal pigmentosa primária, mixomas cardíacos, cutâneos ou vaginais, adenomas hipofisários funcionantes, neoplasia testicular, adenoma ou carcinoma de tireóide e cistos ovarianos. Cerca de $70 \%$ dos indivíduos diagnosticados com Complexo de Carney têm pais afetados e $30 \%$ apresentam a forma esporádica da doença. O complexo de Carney esporádico é raro, o que dificulta ainda mais o diagnóstico. Apresentamos um caso de uma paciente de 24 anos com schwanoma de células fusiformes e carcinoma papilífero de tireóide, tais achados, remetem ao diagnóstico de suspeição de Complexo de Carney.

DESCRITORES: Complexo de Carney; Neoplasia endócrina múltipla; Neurilemoma; Carcinoma papilar/diagnóstico; Neoplasias da glândula tireoide/diagnóstico.

\section{INTRODUÇÃO}

Complexo de Carney (CNC) é uma doença rara; um tipo de neoplasia endócrina múltipla familiar, de herança autossômica dominante. Apresentam várias neoplasias em diferentes órgãos e sistemas ${ }^{1}$.

O Carcinoma Papilífero de Tireoide é o tumor mais prevalente e o que apresenta melhor prognóstico dentre todas as neoplasias malignas de tireoide ${ }^{2}$. É um tumor

\begin{abstract}
Carney complex is a rare form of familiar multiple endocrine neoplasia of autosomal dominant inheritance. Is associated with changes in cutaneous and mucosa pigmentation, adrenal nodular pigmental disease, primary cardiac, cutaneous or vaginal myxomas, pituitary adenomas, testicular neoplasm, nonfunctioning adenoma or carcinoma of thyroid and ovarian cysts. Approximately $70 \%$ of individuals diagnosed with Carney complex have parents affected and 30\% present the sporadic form of the disease. Sporadic Carney complex is rare, which makes the diagnosis even more difficult. We present a case of a female patient, 24 years old with Schwanoma of fusiform cells and thyroid papillary carcinoma, such findings, refer to diagnosis of suspicion of Carney Complex.
\end{abstract}

KEYWORDS: Carney complex; Multiple endocrine neoplasia; Neurilemmoma; Carcinoma, papillary/diagnosis; Thyroid neoplasms/diagnosis.

encontrado 2 a 3 vezes mais em mulheres ${ }^{3}$. Está associado a um prognóstico favorável, todavia, a mortalidade e o risco de recorrência dependem de características do tumor e do paciente, quando analisadas em conjunto ${ }^{4}$.

Os schwannomas são tumores benignos, solitários, encapsulados e de crescimento lento. Originam-se nas células de Schwann neoplásicas diferenciadas. O schwannoma

1.Acadêmico do $5^{\circ}$ ano de Medicina, Faculdade Atenas, Paracatu-MG, Brasil. Email: luilson-junior@hotmail.com.

2.Médica Endocrinologista, Chefe do Departamento de Endocrinologia e Metabologia da Faculdade Atenas, Paracatu, MG, Brasil.

Email: deboraendocrino@yahoo.com.

Autor correspondente: Luilson Geraldo Coelho Júnior. Rua Bernardo Caparucho, 30 Apto. 4 - Bela Vista, CEP: 38600000 - Paracatu, MG, Brasil. Email: luilson-junior@hotmail.com. 
melanocítico é uma variante dessas neoplasias; existem dois tipos de schwannomas melanocíticos: o esporádico e o psamomatoso; sendo que o psamomatoso correlaciona-se com $50 \%$ dos casos de Complexo de Carney $^{5,6}$.

O objetivo deste trabalho é descrever um caso de Complexo de Carney (CNC) em uma paciente jovem, que apresentou dschwannoma melanocítico esporádico e carcinoma papilífero de tireóide, além de apresentar uma revisão sobre a doença, abordando os achados clínicos, laboratoriais e genéticos.

\section{RELATO DE CASO}

Paciente de 24 anos, feminino, em 2013 notou lesão em região cervical anterior direita com seis meses de evolução, sem sintomas compressivos e sem outras queixas associadas. Previamente hígida, sem uso regular de medicamentos. História familiar sem achados significativos. Exame físico cardiovascular, respiratório e abdominal sem alterações. Realizado punção aspirativa de agulha fina (PAAF) da lesão em região cervical, evidenciando lesão compatível com schwannoma melanocítico em 2013.

Realizada, em 2014, ultrassonografia de tireóide; com nódulos em ambos os lobos tireoidianos lobo D com nódulo de $8 \times 6 \mathrm{~mm}$, pouco preciso, sem halo e com microcalcificações. Lobo E com nódulo $10 \times 7 \mathrm{~mm}$, hipoecogênico, com halo hipoecoico. Realizado PAAF em lobo tireoidiano direito e esquerdo no dia 30/05/2014, ambos os nódulos com suspeita de carcinoma papilífero detireóide-Bethesda V.

Realizada tireoidectomia total em 15/07/2014, o exame anatomopatológico evidenciou carcinoma papilífero clássico multifocal, dimensões de $1,3 \mathrm{~cm}$ e $1,0 \mathrm{~cm}$, parcialmente encapsulados, lobo direito e esquerdo, sem infiltração angiolinfática, sem extensão extratireoidiana focal, margens cirúrgicas livres. Bócio multinodularcolóide e tireoidite de Hashimoto.

Em virtude da associação dos tumores, a paciente foi submetida a exame de Ecocardiograma transtorácico para avaliar a possibilidade de apresentar mixomas cardíacos, porém o achado encontrado foi apenas hipertrofia concêntrica leve. O ecocardiograma transtorácico, realizado no dia 21/08/14, evidenciou, ventrículo esquerdo (VE) com espessura aumentada, em grau leve, discreta regurgitação mitral ao Doppler. Hipertrofia ventricular esquerda leve concêntrica; fração de ejeção ventricular esquerda de $75 \%$.

Baseado na avaliação clínica e nos achados histopatológicos foi realizado o diagnóstico de Complexo de Carney.

\section{DISCUSSÃO}

As síndromes de neoplasias endócrinas múltiplas (NEM) compreendem as do tipo 1 (NEM 1) e 2 (NEM 2), a síndrome de von Hippel-Lindau, a neurofibromatose tipo 1 e o Complexo de Carney. São síndromes genéticas, complexas, de transmissão autossômica dominante e ocorrem a partir da ativação ou inativação de diferentes genes que atuam na regulação da proliferação celular ${ }^{7}$.

É necessário diferenciar os termos Complexo de Carney e síndrome ou tríade de Carney, haja vista, compreenderem entidades clínicas totalmente diferentes. A síndrome de Carney é uma doença rara, não hereditária e compreende a associação de leiomiossarcoma gástrico, condroma pulmonar e paraganglioma extra-adrenal ${ }^{8}$. O Complexo de Carney se associa diversos tumores, dentre eles, tumores cardíacos, endócrinos, cutâneos, do sistema nervoso e lesões cutâneas 9 .

O Complexo de Carney tem herança autossômica dominante, penetrância e expressividade variável, ligada a dois loci: 17q22-24 e 2p16, não condicionando diferenças no fenótipo da doença ${ }^{10}$. O gene PPKAR1A (proteinkinase A type 1 a regulatorysubunit) localizado na banda 24 do braço longo do cromossoma 17 (17q24) seria o responsável por originar a doença; ou seja, os casos de complexo de Carney têm sido associados a mutações nesse gene.

O gene PRKAR1A tem ação supressora tumoral, sendo responsável pela produção da subunidade reguladora tipo 1-alfa da proteína quinase A. Esta proteína está envolvida com importantes vias da sinalização endócrina. A subunidade reguladora tipo 1-alfa inibe a função da proteína quinase $\mathrm{A}$, e a mutação de PRKAR1A origina uma subunidade com função praticamente nula, aumentando por conseqüência a sinalização intracelular da proteína quinase $\mathrm{A}$ levando à hiperatividade endócrina e formação de tumores ${ }^{8,10}$.

A maioria dos casos de Complexo de Carney é familiar, representando, aproximadamente, 70\%. Há também alguns esporádicos, caracterizados por uma mutação nova, representando $30 \%$ dos casos, os quais são documentados com siglas LAMB lentigos, mixomas atriais e nevo azul) e NAME (nevo, mixomas atriais e efélides). Aproximadamente 300 a 500 pacientes em todo mundo são acometidos ${ }^{11}$.

O Complexo de Carney é uma neoplasia endócrina múltipla rara, sendo descrito pela primeira vez por J.A. Carneyem $1985^{12}$. Pode acometer diferentes órgãos gerando lesões como, pigmentação cutânea com distribuição típica (lábios, conjuntiva, mucosa vaginal e peniana), mixomas (cutâneo e mucosa), mixoma cardíaco, mixomatose mamária ou imagem na ressonância magnética sugestiva do diagnóstico, doença nodular adrenocortical pigmentada primária, acromegalia - adenoma produtor de GH, tumor de grandes células calcificadas de Sertoli ou calcificações características no ultrassom testicular, neoplasia de tireóide ou múltiplos nódulos hipoecóicosao ultrassom, schwanomamelanótico, nevos azuis múltiplos, adenoma mamário ductal (múltiplo) e Osteocondromixoma ${ }^{9,11,13}$.

Em relação às manifestações clínicas do Complexo de Carney, a mais frequente é a pigmentação cutânea, 
acometendo $77 \%$ dos pacientes; em relação aos mixomas, os cardíacostem prevalência de $53 \%$ e os cutâneos $33 \%$; já a doença adrenocortical nodular pigmentada primária (PPNAD), uma forma de hiperplasia adrenocortical bilateral, acomete $26 \%$ dos pacientes. Outras manifestações, presentes e não muito comuns são: tumores de células de Sertoli (23\%), acromegalia clinicamente evidente (10\%), schwanoma melanótico (10\%), nódulos tireóideos (5\%) e adenoma ductal de mama em $1 \%{ }^{9}$.

As alterações clínicas sugestivas do diagnóstico de Complexo Carney são: lentigos solares; manchas cafécom-leite; IGF-1 elevado, TTGo anormal ou resposta paradoxal do GH durante teste do TRH na ausência de acromegalia clínica; cardiomiopatia; fístula pilonidal; história familiar de síndrome de Cushing, acromegalia ou morte súbita; múltiplos lipomas, skintags ou outras lesões de pele; póliposcolônicos, usualmente em associação com acromegalia; hiperprolactinemia, usualmente leve e quase sempre associada à acromegalia clínica ou subclínica; nódulo tireóideo único em paciente jovem ou múltiplos em paciente idoso detectados por ultrassonografia (USG) e história familiar de carcinoma de cólon, tireóide, pâncreas e ovário; tumores malignos ou benignos múltiplos ${ }^{9,13}$.

$\mathrm{O}$ diagnóstico da doença é feito baseando-se na presença de critérios diagnósticos. Considera-se como portador da síndrome o doente que apresentar dois ou mais critérios maiores, ou, um critério maior e um suplementar. Além disso, os critérios presentes devem ser confirmados com histologia, testes bioquímicos e exames de imagem. Os critérios diagnósticos são ilustrados na Tabela 1.

Tabela 1. Critérios diagnósticos para o Complexo de Carney

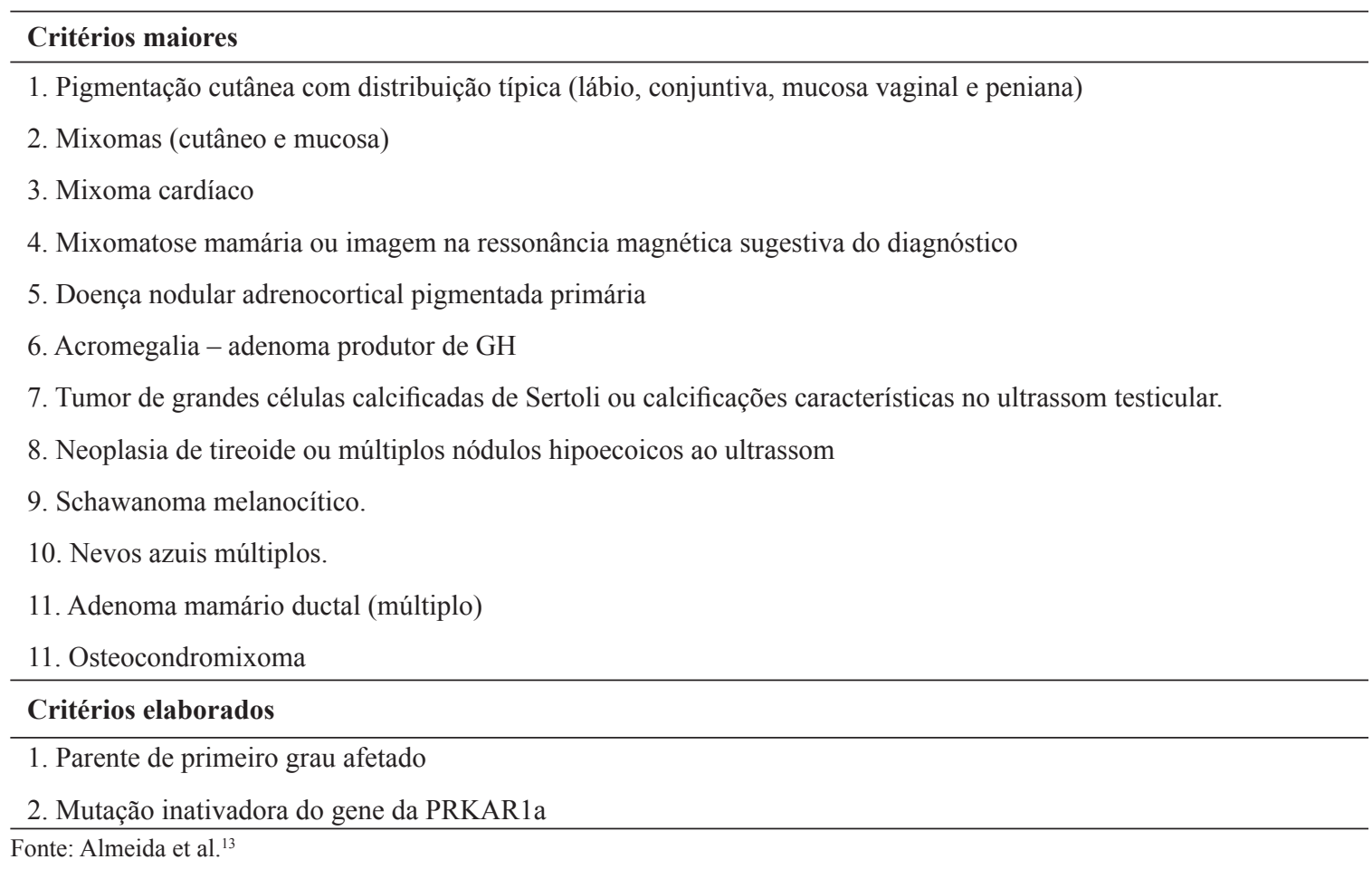

É de suma importância a suspeição do quadro acima, uma vez que o Complexo de Carney trata-se de uma síndrome com inúmeros componentes de tumores neuroendócrinos que podem se manifestar a qualquer momento da vida da paciente. A suspeita clínica possibilita que o diagnóstico seja feito de forma mais precoce, uma vez que são tumores de crescimento lento, com quadro clínico obscuro o que, consequentemente, acarreta diagnósticos tardios, aumentando a morbimortalidade associada à doença.

CONFLITOS DE INTERESSE: Os autores declaram não haver conflito de interesse. 


\section{REFERÊNCIAS}

1. Briassoulis G, Quezado M, Lee CC, Xekouki P, Keil M, Stratakis CA. Myxoma of the ear lobe in a 23-month-old girl with Carney complex. J Cutan Pathol. 2012;39(1):68-71. doi:10.1111/j.1600-0560.2011.01786.x.

2. Camandaroba MPG, Mata LS, Almeida LB, Miranda JS, Neves MP. Carcinoma papilífero da tireoide associado à tireoidite de Hashimoto: uma série de casos. Rev Bras Cancerol. 2009;55(3):255-61. Disponível em: http://www. inca.gov.br/rbc/n_55/v03/pdf/59_artigo7.pdf.

3. Welker MJ, Orlov D. Thyroid nodules. Am Fam Physician 2003;67:559-66. Available from: http://www.aafp.org/ afp/2003/0201/p559.html.

4. Barbosa MM, Sá GM, Lima RRMA, Kligerman J, Farias TP, Chagas MJ. Carcinoma papilífero de alto risco da glândula tireóide: influência dos fatores prognósticos em 126 pacientes. Rev Col Bras Cir. 2001;28(6):397-400. http:// dx.doi.org/10.1590/S0100-69912001000600002.

5. Santaguida C, Sabbagh AJ, Guiot MC, Del Maestro RF. Aggressive intramedullary melanotic schwannoma: case report. Neurosurgery. 2004;55(6):1430. doi: 10.1227/01. NEU.0000143617.25417.68.

6. Welling LC, Guirado VM, Tessari M, Felix AR, Zanellato C, Figueiredo EG, et al. Spinal melanotic schwannomas. Arq Neuropsiquiatr. 2012;70(2):156-7. http://dx.doi.org/10.1590/ S0004-282X2012000200018.

7. Hoff AO, Hauache O. Neoplasia endócrina múltipla tipo 1: diagnóstico clínico, laboratorial e molecular e tratamento das doenças associadas. Arq Bras Endocrinol Metab. 2005;49(5):735-46. http://dx.doi.org/10.1590/S000427302005000500014 .

8. Wilkes D, MacDermott D, Basson C. Clinical phenotypes and molecular genetic mechanisms of Carney complex. Lancet. 2005;6:501-8. doi: 10.1016/S1470-2045(05)70244-8.

9. Stratakis CA, Kirschner LS, Carney JA. Clinical and Molecular Features of the Carney complex: diagnostic criteria and recommendations for patient evaluation. J Clin Endocrinol Metab. 2001;86:4041-6. Available from: http:// press.endocrine.org/doi/pdf/10.1210/jcem.86.9.7903.

10. Chinchurreta-Capote A, Trueba A, Hernández FJ, Piñas P, López S, Tena ME, et al. Manifestaciones oftalmológicas del síndrome de Carney. Arch Soc Esp Oftalmol. 2006;81(12):70912. Disponível em: http://scielo.isciii.es/scielo.php?script=sci arttext\&pid=S0365-66912006001200007.

11. Bertherat J. Carney complex (CNC). Orphanet J Rare Dis 2006;1:21. doi: 10.1186/1750-1172-1-21.

12. Carney JA, Gordon H, Carpenter PC, Shenoy BV, Go VL. The complex of myxomas, spotty pigmentation, and endocrine overactivity. Medicine (Baltimore). 1985;64(4):270-83.

13. Almeida MQ, Villares MC, Mendonça BB. Carney complex: a case report and literature review. Arq Bras Endocrinol Metab. 2004;48(4):544-54. http://dx.doi.org/10.1590/S000427302004000400016 . 